\title{
Metaphoric Term as Translation Unit of Technical Text
}

\author{
Larisa Fedyuchenko* \\ Institute of Social Sciences and Humanities, 625003, Tyumen State University, Tyumen, Russia
}

\begin{abstract}
The article considers the technical metaphoric term as a dynamic cognitive structure, which contains a fragment of the global technical picture. The author starts with a critical review of the existing approaches to the definition of a translation unit and suggests that this term should be considered as a dynamic unit of the text's semantic structure. In this regard, the procedure is not limited to a simple extraction of a translation unit in the source text, but it leads to a complex linguistic analysis at the pretranslation stage. To extract the translation unit, the author suggests using a criterion of an unexpected collocation, which is why the metaphoric term is the subject of the study. Having justified the approach, the author presents the stages of the carried out linguistic analysis. Based on the results, the author formed fourteen thematic groups and described typical collocations of the structural elements. In the course of the analysis, the following functions of the metaphoric terms were singled out: 1) operational function, 2) shaping function, 3) intermediary function, 4) transfer function, 5) comprehension function, and 6) interpretation function. Such integrated approach to the analysis of the translation unit ensures adequate translation and minimizes critical translation errors.
\end{abstract}

\section{Introduction}

It is a well known fact that the translation starts with the definition of the translation unit, since the procedure of extracting the translation unit is the primary stage of the text understanding, and as we know, translation is impossible without a complete understanding of the source text. To support our statement, we bring T. S. Serova's point of view, who notes that comprehension and understanding of the entire text or its single fragment precedes the translation. Comprehension starts with the segmentation of the source text into segments taking into account the thematic content and development of meaning and ends with a curtailment of the thematic content itself and meaning [1].

M. Ballard, discussing the essence of the translation unit, says the following: "Professional translators instinctively think in terms of translation units when they want to assess or describe their work and it proves to be equally necessary and useful to theoreticians when they want to analyse the translator's work." [2].

The modern translation studies views the procedure of translation unit extraction as one of the most complex and still ambiguous issues. There are different points of view on this problem: from recognizing the most minimal language units (phonemes) as such and ending with a complete denial of the existence of such unit (for example, A. D. Schweitzer [3]).

This topic remains relevant, especially in the context of an active development of automated translation systems, for which segmentation of the text into meaningful segments is important. The problem of extracting a translation unit is relevant for solving a whole range of issues: automated machine translation, training in translation technology, studying the translation process, comparative analysis of texts and others.

In this article, we consider the metaphoric term as the translation unit, since the term is the main and distinctive unit of a technical text capable to convey technical knowledge. The metaphoric term in its turn serves as a kind of a condensed cognitive model with the implicit technical knowledge necessary for understanding the whole text and the subsequent adequate translation.

We explain the choice of a technical text as an object of the research by two reasons: firstly, by the growing demand for this type of translation in the market; secondly, by the difficulties in translating technical terms that professional translators and students studying technical translation face with. Most universities where technical translators are trained give serious consideration to the problem, as evidenced by the literature [4].

A modern technical translator should not only be able to translate, but also to understand topics, possess basic technical knowledge, that is, to be a universal specialist who combines linguistic and non-linguistic competencies. In support of this, we can quote $\mathrm{N}$. Gavrilenko and S. Dmitrichenkova: "Current analysis of tasks performed by translation agencies shows steady growth of demand for translation of technical texts, the growing number of translation areas and the emergence of new specialties, such as a project manager, a translator-localizer, a translator-terminologist, etc. This profession is undergoing significant changes and, accordingly, it requires new approaches to training of translators." [5]. 


\section{Technical translation and technical communication}

Technical communication is the process of exchanging technical information in a professional environment. As in any other type of communication, the basic unit of information transmission here is the text, or more precisely - technical text. It is important, from our point of view, to distinguish between technical text and special text. This distinction is difficult to determine, because the concept of 'technical text' does not have a clear definition. As pointed out by T. Copeck, K. Barker, S. Delisle, S. Szpakowicz, and J.-F. Delannoy "“Technical text' is not a term defined in a theory. It is a notion in everyday use, sufficiently common that even academic writers do not generally feel they need to provide an explicit definition." [6].

Nevertheless, in this study, we propose considering a special text as a text which contains general scientific and technical terminology and it is aimed at a clear, accurate and maximally complete presentation of a particular theory or approach [7]. Technical text is a text whose purpose is to transfer a specific knowledge about individual subjects (an apparatus, a system, a mechanism, a spare part, etc.) in a certain field of technology. As Ahmed Alaoui writes, technical text deals "with the application of the knowledge of exact sciences, such as computer science, chemistry and engineering.... scientific texts deal with knowledge obtained through experimentation and observation of various phenomena, technical texts relate to the application of such knowledge." [8].

Based on this distinction, we can talk further about the specifics of the technical translation, which we regard as a kind of special translation and, following Sameh Saad Hassan, define it as "the translation of materials dealing with technological subject areas and using the specialised terminology of scientific and technological information." [9].

The first difference between technical translation and other types of translation is that this translation cannot be performed without at least basic technical knowledge that is the basis for understanding any technical text. Almost all scientists and translators dealing with the technical translation, regardless of a pair of working languages, specify it: U. V. Khorechko, A. I. Scherbinin, I. O. Lebedeva, Li Bao Gui, A. E. Sentsov [10].

The second difference is that an analysis and understanding of terminology precedes technical translation, since the main unit of the technical text is the term that contains the technical knowledge necessary to understand the general purpose of the source text. As Radegundis Stolze notes, "In technical translation the terminology must be checked conscientiously." [11]. Thus, we can say that the term can and should be the basic translation unit of the technical text.

\section{Metaphoric term as a translation unit}

The term translation unit was first introduced by French scientists J. P. Viney and J. Darbelnet in 1958 in their work Stylistique comparée du français et de l'anglais, in which they defined the term as follows: "“'le plus petit segment de l'énoncé dont la cohésion des signes est telle qu'ils ne doivent pas être traduits séparément" (the smallest segment of the utterance, where the cohesion of the signs is such that they must not be translated separately)." [12].

Since then, different scientists, arguing about the translation unit, apply different approaches to its interpretation. Thus, the Russian translation tradition understands it as the minimum segment of the source text that corresponds to such elementary meanings of the mediator language that can refer to some segments of the target text [13].

In the Western translation studies, the interpretation of this term depends on the approach that the scientist is using. So, from the point of view of the process-oriented approach, the translation unit is "the stretch of source text on which the translator focuses attention in order to present it as a whole in the target language" [14]. SnellHornby defines the translation unit as "a cohesive segment lying between the level of the word and the sentence." [15]. Silescovic and Lederer define the translation unit as "a unit of sense gathered from a segment of discourse (a small number of words) that will contribute to the construction of the deverbalized sense of the whole message to be re-expressed in the target language." [2]. P. Newmark claims that "all lengths of language can, at different moments and also simultaneously, be used as units of translation", but "operatively, most translation is done at the level of the smaller units (word and clause)" [16].

C. Nord considers the translation units through the prism of the functional approach, according to which the translation unit is not a separate element of the text, but a whole set of elements that have similar functions with elements of the source text: "these units are not structurally determined text segments but combinations of purpose-bound elements spread over the whole text forming chains or even networks." [12].

However, regardless of the approaches, most scientists agree that the translation unit is the minimum unit of the text that the translator works with, i.e. this is the minimum segment of the text's semantic structure.

In our research, we proceed from the thesis that the translation unit is a dynamic unit that has an ability to change throughout the text, depending on the development of the meaning (plot) of the source text. In this regard, the translation unit should be determined basing on the specific meanings the translator is currently working with. Harry J. Huang and Canzhong Wu have a similar view, believing that only practicing translators should determine the translation unit, since this is a purely operational unit of the text: "The UT should not have been defined by scholars in the first place, but should have been synthesized from practice." [17].

Thereupon, let us dwell on the reasons for choosing the metaphoric term as a translation unit of the technical text. 
First of all we should define the term itself. In the broadest sense, a term is a word with a special meaning, which defines a certain special concept; i.e. the term is a graphic and semantic expression of a given concept or a group of concepts. "Terms are the linguistic units that designate our conceptualization of objects, processes, states and attributes in a specialized domain. Therefore, they play a key role in understanding, representing, transmitting, and acquiring specialized knowledge." [18].

Analyzing Russian scientific works on terminology, we came to the conclusion that the cognitive approach is actively being developed (S. V. Grinev, V. F. Novodranova, V. M. Leichik, E. I. Golovanova). In our study, we also follow this approach and define the term as follows: it is a dynamic conceptual structure in which special knowledge is realized. Proceeding from this, we define the metaphoric term as a dynamic epistemological structure formed on the basis of already known general scientific / general technical knowledge, the main function of which is to express the knowledge in a more compact and accessible form.

Terms are the key units of the technical text because they contain the bulk of technical concepts, through which the technical knowledge is transferred; they form the technical picture of the world and are a means of communication among specialists in a certain field; they are a language tool for expressing cognitive information (a key type of information in the technical text). Since any kind of translation is based on a meaningful analysis of the source text, the term, as a means of expressing a special concept in a technical text, is the starting point from which the interpretation of the meaning of the source text begins. It should also be remembered that the term is a unit of a separate terminology system. Using terms, we therefore refer to the terminology as a whole and, thus, acquire technical knowledge in a certain field. From this, it follows that when choosing a term as a translation unit, we regard it not as a minimum unit of text, but as a unit of multi-stage semantic analysis, and the unit is capable to change throughout the text. Thus, the fundamental difference of our approach to extract the translation unit is that we consider it as a dynamic unit, the functions of which are: the formulation of the meaning of the technical text and a concise representation of the technical knowledge.

Despite the fact that the metaphor is not often found in technical texts, we distinguish the metaphoric term as a translation unit. The choice of the metaphoric term as an object of this study is determined by the following reasons:

- metaphor provides an understanding of a special text by a layman;

- metaphor reduces the abstractness of a new special concept (a high degree of abstraction makes it difficult to perceive and understand a special text by a nonspecialist);

- metaphor provides an universal interpretation of the text (absence of ambiguity is one of the main features of a special text);

- metaphor involves the recipient in the process of learning special knowledge;
- metaphor is a cognitive mechanism that operates dynamically [19];

- the technical metaphor can 1) name parts, stressing space; 2) denote actions, stressing time; 3) denote qualities, stressing neither time nor space; or 4) create models, stressing both time and space [20];

- metaphor is a valuable tool in enriching the vocabulary of a technical or scientific field and in enabling the experts in a domain to spread their specialized knowledge amongst laymen.

Thus, analyzing the metaphor as a structural element of the technical text, Raluca Ghentulescu distinguishes the following main functions of it:

- to designate a certain discovery or invention in a meaningful way;

- to explain a theory in comprehensible terms, so that science and technology could be popularized;

- to present the outcomes of a technical-scientific breakthrough in a manner that can be easily understood. To designate a certain discovery or invention in a meaningful way;

- to explain a theory in comprehensible terms, so that science and technology could be popularized;

- to present the outcomes of a technical-scientific breakthrough in a manner that can be easily understood [21].

We identify one more important function of the metaphor in the technical text - the educational one. When teaching technical translation, the metaphoric terms allow students to associate new unfamiliar concepts with those already known and understandable, and, thereby, stimulate them to search for new meanings and ways of translation. In addition, metaphoric terms and technical texts have one common property - a dynamic structure, since the main purpose of a technical text and terms is to convey a new knowledge, to help understand and assimilate it, to teach how to apply it in practice. As noted by Ana Roldán-Riejos and Georgina Cuadrado, "Metaphor is a cognitive mechanism that operates dynamically. Metaphor has a multimodal nature and therefore can appear in different scenarios activating various perception codes. Metaphor has a multimodal nature and therefore can appear in different scenarios activating various perception codes." [19].

There are different criteria for extracting translation units in the text. Thus, a number of scientists propose a frequency criterion, that is, those units of the text that are most often used in a certain body of texts can be regarded as translation units. As a rule, these units are well known to the recipient, they are easily recognized in the text. For example, Noemie Elhadad supports this point of view: "Psycholinguistic research has shown that frequency of word usage in a large corpus is a good predictor of its familiarity." [17]. But it is appropriate to apply this approach to the large corpus of texts and, most often, this extraction occurs automatically. As for the individual text of a small size (especially when it comes to the teaching translation), this criterion does not justify itself.

When training the translation, we propose the use of the criterion of unexpected word collocation, that is, we take the terminological phrase with a metaphoric term in 
its structure for the translation unit. We also believe that we should not limit ourselves to a simple extraction of the metaphoric terms, since any translation unit requires linguistic analysis before translation. Such an analysis allows us to obtain a detailed technical knowledge about the topic and thereby to form a separate fragment / fragments of the general technical knowledge, which is necessary to achieve an adequate translation. In this regard, we propose to conduct a linguistic analysis at the pre-translation stage (the stage of the semantic analysis of the source text) and we teach the students-translators to carry out it. Next, we will dwell on the stages of the analysis.

The aim of the first stage is to extract and characterize the figurative components that underlie the metaphorical shift in the selected terminological word combinations; the aim of the second stage is to determine the type of collocating components of the analyzed word combinations.

The study material is the metaphors (413 units), which we extracted from the corpus of technical texts on oil and gas equipment (650,000 word token), which is used as a learning material in the technical translation course.

At the first stage of the study, we identified figurative components, which became the reason for the metaphorical shift. As we know, the metaphor is formed on the basis of the already known concept, which is most often expressed by the word of general language, but in the technical text, a part of such words acquires a special meaning; consequently, the following factors were the criteria for selecting the figurative component: a literary understanding of the word of general language and an unexpected collocation of the words of general language.

For example, wildcat well (an exploratory well); in this word collocation, the word of general language well (a spring or natural source of water) - acquires a special meaning (a well from which petroleum is obtained) and it has an unexpected collocation with the words wild and cat (a wild cat is a small predator native to Europe, the western part of Asia, and Africa); literal translation - a source of water of a a small predator does not make any sense (even within the narrow context), therefore, such unexpected collocation leading to inadequate literal understanding, gives us a reason to regard such a phrase as a metaphor, and wildcat we consider as a figurative component.

Based on the conducted component analysis, we have formed the thematic groups of metaphoric terms. Every repeating figurative component specified the name of each group. As a result, we received 14 groups, which are presented in the table below.

As we can seen from the data in the table, the main figurative components used in the terminological nomination process are anthropomorphic in character, since they affect the image of a person, his/her character or physical data: toe valve, simple shoulder test, female unit. The use of these figurative components indicates that such terms belong to the general technical ones, since the metaphors embedded in them are well known to a wide range of people and do not require further explanation; such metaphors are classed as dead metaphors. At a later stage, we will more clearly illustrate this statement basing on the analysis of the collocations.

Table 1. Thematic groups of metaphoric terms.

\begin{tabular}{|l|l|c|}
\hline$\#$ & Group Name & Quantity of Terms \\
\hline 1. & Mixed & $88(21.3 \%)$ \\
\hline 2. & Quality & $54(13 \%)$ \\
\hline 3. & Hole & $46(11.1 \%)$ \\
\hline 4. & Parts of the human's body & $46(11.1 \%)$ \\
\hline 5. & Human & $40(9.7 \%)$ \\
\hline 6. & Clothes / Shoes & $29(\approx 7 \%)$ \\
\hline 7. & Movements & $26(6.3 \%)$ \\
\hline 8. & Traveling / Transport & $21(5 \%)$ \\
\hline 9. & Building & $16(3.8 \%)$ \\
\hline 10. & Life & $12(2.9 \%)$ \\
\hline 11. & Sport & $12(2.9 \%)$ \\
\hline 12. & Medicine & $9(2.2 \%)$ \\
\hline 13. & Animal / Bird & $8(1.9 \%)$ \\
\hline 14. & Plant & $6(1.5 \%)$ \\
\hline
\end{tabular}

Also, according to the table, we can see that the mixed group is the most numerous one. In the mixed group, we included the metaphoric terms containing two figurative components, which did not allow them to be included in any particular group, for example: ball sleeve competition, conventional toe sleeve system (part of a person's body + detail of clothing), forklift pocket (cutlery + garment detail), mouse hole (animal + hole), seabed water injection (interior detail + medicine). Several figurative components in one terminological phrase indicate a higher degree of abstraction of the term. This thesis is justified by the fact that two or more figurative components in the same terminological phrase form an extended metaphorical model with the deep semantic links among the figurative components. In addition, in a number of cases, the terminological word unit includes only metaphoric terms without a general technical term. In such cases, it is practically impossible to recognize such a term and formulate its meaning without any additional specialized knowledge. Consequently, such terms can be considered as highly specialized, requiring additional knowledge and interpretation.

At the next stage of the study, we analyzed the collocation of the elements of the selected word combinations. The aim of this stage is to trace the collocation of metaphors with certain types of words: general technical terms, general scientific terms, highly technical terms, words of the general language. It should be noted, that we deliberately name all the structural elements of the terminological phrase as words, since from the point of view of the recipient (a student-linguist) of a foreign technical text, all the collocation elements are words at the initial stage of reading the text. Although intuitively based on the elementary technical knowledge, students understand that they are dealing not with words, but with terms.

Thus, we divided each phrase into structural elements, after that we correlated each element with one of the types of the above-mentioned word-terms. The criterion of reference to this or that type was the occurrence in a specialized dictionary: a general scientific / general 
technical dictionary, an industry dictionary, a corporate glossary, a translation database, a dictionary of commonly used words, or the presence of a definition / explanation in the text from which the phrase was extracted.

Below we give the results of the analysis of the component collocations that make up the structure of metaphoric terms. The results are presented for the first four thematic groups (Quality, Hole, Parts of the human body, Human).

Table 2. Collocations of the components of terminological word combinations.

\begin{tabular}{|c|c|}
\hline Group Name & Numerical rating \\
\hline Quality & $\begin{array}{l}\text { - metaphoric term + general } \\
\text { technical term }(61.1 \%) ; \\
\text { - metaphoric term }+ \text { highly } \\
\text { technical term }(24.07 \%) ; \\
\text { - metaphoric term }+ \text { general } \\
\text { scientific term }(9.2 \%) ; \\
\text { - metaphoric term + word of } \\
\text { general language }(5.5 \%) .\end{array}$ \\
\hline Hole & $\begin{array}{l}\text { - metaphoric term + general } \\
\text { technical term }(28.2 \%) ; \\
\text { - metaphoric term }+ \text { highly } \\
\text { technical term }(28.2 \%) ; \\
\text { - metaphoric term + word of } \\
\text { general language }(28.2 \%) ; \\
\text { - metaphoric term + general } \\
\text { scientific term }(15.2 \%) .\end{array}$ \\
\hline $\begin{array}{l}\text { Parts of the } \\
\text { human body }\end{array}$ & $\begin{array}{l}\text { - metaphoric term + general } \\
\text { technical term }(47.8 \%) ; \\
\text { - metaphoric term }+ \text { highly } \\
\text { technical term }(41.3 \%) ; \\
\text { - metaphoric term + general } \\
\text { scientific term }(8.7 \%) ; \\
\text { - metaphoric term + word of } \\
\text { general language }(2.2 \%) .\end{array}$ \\
\hline Human & $\begin{array}{l}\text { - metaphoric term + general } \\
\text { technical term }(45 \%) ; \\
\text { - metaphoric term + word of } \\
\text { general language }(35 \%) ; \\
\text { - metaphoric term }+ \text { highly } \\
\text { technical term }(17.5 \%) ; \\
\text { - metaphoric term + general } \\
\text { scientific term }(2.5 \%) .\end{array}$ \\
\hline
\end{tabular}

As can be seen from the above-mentioned results, the dominant collocation is the metaphoric term + the general technical term. In this case, we define the general technical term as a term used in several fields of science and technology, which, as a rule, has the same interpretation, despite different spheres of use. In fact, general technical terms are precise concepts that do not require a special explanation by the specialist; they are a kind of the basis of our technical knowledge of the world.

The predominance of collocations of the metaphoric term and the general technical term indicates that the general technical term carries out an explanatory function, i.e. explains the metaphor, as if transferring technical knowledge from the specialists' level into the amateur's one, thereby making technical knowledge more accessible. In our case (training technical translation), this is an important factor in the process of teaching to extract the terms in a source text. That is, the factor of unexpectedness - a nontypical collocation of the wellknown general technical term with the metaphoric termshould be used as a criterion for recognizing special vocabulary in a technical source text.

If we calculate the collocations of the metaphoric term with the highly technical term, we will see that these combinations are not as frequent as the collocations of the metaphoric term and the general scientific term or the collocations of the metaphoric term and the word of general language. That is, the share of highly technical metaphoric terms with a high degree of abstraction is small ( $\approx 28 \%$ ) in the corpus of texts that we are analyzing, which indicates that special lexicon is preferred in special technical texts, thus providing one of the basic style requirements: accuracy and clarity of presentation.

\section{Conclusion}

To summarize, we can draw several conclusions.

Firstly, we regard the translation unit as a dynamic unit of the semantic structure of the text.

Secondly, the metaphoric term in the technical text performs a number of functions: 1) the operational function; 2) the function of forming the technical picture of the world; 3) the mediator function; 4) the function of technical knowledge transfer; 5) the function of understanding the source text, and 6) the function of interpreting the highly technical terminology.

Thirdly, the pre-translational linguistic analysis of the translation unit provides an adequate translation and minimizes critical translation errors, which ensures a high quality of translation and a fluent professional communication.

I express my gratitude to Prof. V. D. Tabanakova for taking time to read the draft and for useful advice that helped me when writing the article.

\section{References}

1. T.S. Serova, Language and Culture 2, 106 (2010).

2. M. Ballard, Handbook of Translation Studies. John Benjamins Publishing Company 1, 437 (2010)

3. A.D. Shveitser, Theory of Translation: status, problems and aspects (Moscow "Nauka", 1988)

4. P.J. Mitchell, N.I. Tomsk State University Journal 394, 53 (2015)

5. N. Gavrilenko, S. Dmitrichenkova, XLinguae 10(4), 126-137 (October 2017)

6. T. Copeck, K. Barker, S. Delisle, S. Szpakowicz, J-F. Delannoy, Language Sciences, 19 (4), 391-423 (October 1997) 
7. E.V. Chistova, Philological Sciences. Issues of Theory and Practice, Tambov: Gramota 7 (25), part 2, 201 (2013)

8. A. Alaoui, Engineering and Technology International Journal of Humanities and Social Sciences 9, 10, 3380 (2015)

9. S.S. Hassan, Translation \& Interpreting 9, 2, 67 (2017)

10. U.V. Khorechko, A.I. Scherbinin, I.O. Lebedeva, Li Bao Gui, A.E. Sentsov, Procedia - Social and Behavioral Sciences 215, 43 (2015)

11. R. Stolze, The Journal of Specialised Translation 11, pp. 124-142 (2009)

12. Ch. Nord Functional translation units Mauranen, A. \& T. Puurtinen 1997. Translation - Acquisition Use. AFinLA Yearbook 1997. Publications del'Association Finlandaise de Linguistique Appliquée 55. Jyväskylä. 41-50

13. L.L. Nelyubin, Explanatory Translation Dictionary, 3rd ed., (Moscow, "Flinta", "Nauka", 2003)
14. Routledge Encyclopedia of Translation Studies, edited by M. Baker, (London and New York, 2001)

15. M. Snell-Hornby, Translation Studies. An Integrated Approach (John Benjamins Publishing Company, Amsterdam/Philadelphia, 1988/1995)

16. P. Newmark, A Textbook of Translation (PrenticeHall Internationa, 1988)

17. H.J. Huang, C. Wu, Meta, 54 (1), 110-130 (2009)

18. J.C. Gil-Berrozpe, P. Faber, Temas actuales de terminología y estudios sobre el léxico, Interlingua 172. Granada: Comares (2017)

19. A. Roldán-Riejos, G. Cuadrado, Procedia - Social and Behavioral Sciences 212, 271-277 (2015)

20. D.R. Butler, Journal of Technical Writing and Communication 16(1), 141-146 (1986)

21. Gh. Raluca, First International Scientific Conference Filko. Conference Proceedings, Stip, 147-154 (18-19 March 2016) 